12 Rouhi, A.M. (2002) Chiral roundup. Chem. Eng. News 80(23), 43-50

13 Rouhi, A.M. (2003) Chiral business. Chem. Eng. News 81(18), 45-55

14 Shah, R.R. and Branch, S.K. (2003) Regulatory requirements for the development of chirally active drugs. In Stereochemical Aspects of Drug Action and Disposition (Eichelbaum, M. et al., eds), pp. 379-399, Springer
15 Miller, S.P. (2001) FDA perspective on quality control for chiral pharmaceuticals. 13th International Symposium on Chiral Discrimination (abstract L/316)

16 Bristol, J.A. and Doherty, A.M. eds. (1984-2003) To Market, To Market. In Annual Reports in Medicinal Chemistry, 19-38, Academic Press

17 Rouhi, A.M. (2003) Chirality at work. Chem. Eng. News 81(18), 56-61
18 Hilts, P.J. (2003) Protecting America's Health: the FDA Business, and One Hundred Years of Regulation. pp. 144-165. Alfred A. Knopf, New York

19 Agranat, I. and Caner, H. (1999) Intellectual property and chirality of drugs. Drug Discov. Today 4, 313-321

20 Anonymous (2003) Patent watch. A new twist on the chiral switch. Nat. Rev. Drug Discov. 2, 424

The Discussion Forum provides a medium for airing your views on any issues related to the pharmaceutical industry and obtaining feedback and discussion on these views from others in the field. You can discuss issues that get you hot under the collar, practical problems at the bench, recently published literature, or just something bizarre or humorous that you wish to share. Publication of letters in this section is subject to editorial discretion and company-promotional letters will be rejected immediately. Furthermore, the views provided are those of the authors and are not intended to represent the views of the companies they work for. Moreover, these views do not reflect those of Elsevier, Drug Discovery Today or its editorial team. Please submit all letters to Steve Carney, Editor, Drug Discovery Today, e-mail: S.Carney@elsevier.com

\section{Advancing in the face of conventional wisdom}

In recent issues of Drug Discovery Today

$[1,2]$, Jurgen Drews and David Cavalla discussed the future productivity of drug discovery. Although they made many insightful and valid comments, I would like to add some points to the overall discussion.

My first point is that most small biotechnology companies are not funded enough to enter a Phase III clinical study. Often, it is not even in their business strategy to enter Phase III development without a major partner on board. Therefore, it might be that the lack of funding and increased discretion of the major pharmaceutical companies play the more important roles in determining which products enter Phase III drug development. This would explain many of David Cavalla's observations, including why there has been an increase in Phase I and II investigations, with a $71 \%$ increase in the time taken in Phase II between 1997 and 2001 (Ref. [2] and references therein).

My second point is that drug discovery could blossom if we recognized the need both for more accurate descriptions of drug-receptor interactions and for safer drugs. I believe that most readers would agree with these two points, although when it comes to Drews' and Cavalla's point that '....without the conviction based on scientific rectitude to advance into uncharted areas in the face of conventional commercial wisdom, medicine will advance little, and the future for the pharmaceutical industry is lacklustre.' [2], we enter a rather strange realm in which we should promote the unusual and more creative scientific ideas to develop better drugs. However, the drug discovery process is not constructed to do this in a way that encourages the funding of the more creative young biotechnology companies or entrepreneurs. Much investor money is risk adverse, so this job is handed over to the well-funded pharmaceutical or biotechnology companies, or to the universities and National Institutes of Health. This is slightly better, although they are all invested in the conventional wisdom (which is often shaped by money and power) and, therefore, have no desire to upset it.

Often, there are rather large egos involved in promoting and keeping scientific theories and ideas in press for possible prestige and potential fame. Yet some of the areas of most need are left wanting for the necessary cutting-edge research. Many diseases have only palliative treatments and many of the drug therapies have serious side effects that have increased morbidity and mortality. Much has been made of the Institute of Medicine report suggesting that from 44000 to 98000 deaths occur annually in the USA because of medical errors [3]. However, the side effects of drugs and drug combinations increase each year, despite increased vigilance from the health care community. Certainly, some of the reported medical errors are due to the improper use of drugs. For the most part, the Food and Drug Administration 
and the pharmaceutical industry produce the safest drugs possible in the ideal dosage range. However, more can be done. It is recognized that many drugs are safe for some people, but can produce serious side effects in others. It is also recognized that the recommended dosage is either too small or too large for some people. These remain significant areas of drug development that are as much an art as a science.

We really do not understand fully how drugs activate receptors, or what the optimal drug dosage is for each patient. Many believe that the future will bring a better understanding of these problems, but the future is a vast realm of information that needs interpretation and perspective. Often, our perspectives on the tough scientific questions concerning drug development are based on intuition, experience and perception. We want the best drugs but we spend billions of dollars on projects that get us no closer to a basic understanding of the underlying biophysical processes. Frequently, this is because we have failed to ask the right questions. How can we design safer, more fault-tolerant medications? What are some of the side effects we can prevent? What produces the response when a drug contacts its cellular receptor? Some partial answers to these questions are that we could prevent drug-receptor desensitization with the right approach [4] and, thereby, enhance the safety and efficacy of many drugs [5]. Conventional wisdom might not want to recognize some of these problems because it wants people to believe that they are receiving the best drugs.

Ironically, this is true, but to make progress, we must take a hard look at those areas in which progress needs to be made, and develop creative alternatives to the conventional wisdom.

\section{References}

1 Drews, J. (2003) Strategic trends in the drug industry. Drug Discov. Today 8, 411-420
2 Cavalla, D. (2003) Biotechnology discovery productivity: a note of caution. Drug Discov. Today 8, 973-974

3 Kohn, L.T. et al., eds (2000) To Err Is Human: Building A Safer Health System, National Academies Press, Washington, DC

4 Lanzara, R. (2003) Agonist/antagonist combinations at the $\beta 1$-adrenergic receptor for preventing receptor desensitization. The Chemweb Preprint Server (http://preprint. chemweb.com/medichem/0302002)

5 Lanzara, R. (2003) Compositions to enhance the efficacy and safety of bio-pharmaceutical drugs. US Pat. 6,593,094

\section{Richard Lanzara}

President and Principal Scientific Officer Bio Balance

30 West 86th Street, New York NY 10024, USA e-mail: rlanzara@bio-balance.com

\section{Dendrimers and protein cages as nanoparticles in drug delivery}

The recent overview by Sanjeeb Sahoo and Vinod Labhasetwar, entitled 'Nanotech approaches to drug delivery and imaging', [1] summarizes efforts in this area well. The article is organized by type of nanostructure and provides examples of polymeric biodegradable nanoparticles, ceramic nanoparticles, polymeric micelles, liposomes, dendrimers, nanocrystals and ferrofluids.

Because the focus of my research group is on multivalent cell-surface recognition processes using dendrimer frameworks, I read this article with much interest. The review cites an example in which dendrimers coated with phospholipids are used as delivery vessels for 5-fluorouracil [2]. This is one of the best examples of dendrimers that encapsulate therapeutic agents. In my research laboratory, we use a variety of isothiocyanates to functionalize dendrimers heterogeneously through thiourea linkages to surface residues $[3,4]$. Although our work is primarily basic research and quite academic, one of our goals is to use surface groups on the dendrimer framework both for targeted delivery and for linking the prodrug to the dendrimer. A nice example from another group demonstrating the use of heterogeneously surface-functionalized dendrimers for targeted imaging describes ${ }^{153} \mathrm{Gd}$-folate dendrimers [5]. Because the synthetic routes are relatively straightforward and heterogeneously functionalized dendrimers are readily attained, dendrimer surface patterning has enormous potential for targeted drug delivery.

When considering nanoscale frameworks for drug delivery, the heart of the issue is clearly the biocompatibility of the frameworks. The nanoparticles and macromolecules might effectively solve many problems such as targeting drug delivery, extending product lifetime and increasing aqueous solubility, but these improvements often come at a cost because of size. The clearance rate of the nanomaterials might be high, and the likelihood of the nanoparticle lodging in certain organs such as the liver could make adoption of nanoparticles impractical in many instances. In addition, some frameworks might be too large to fit through small capillaries. One of my concerns is that many researchers who develop nanoparticle drug delivery systems might be overlooking the potential immunogeneity of the frameworks when they are considering them for clinical use. Luckily, those of us whose research is focused on the development of nanoparticles can draw from reports of polymer-drug conjugates [6]. Although the nanoparticles are often smaller and less polydisperse than the polymers, problems with the toxicity of the framework might be similar.

Like Sahoo and Labhasetwar, I feel that nanoparticles do play an important 